\title{
Clinical presentation and need for treatment of a cohort of subjects accessing to a mental illness prevention service
}

\author{
Marco Solmi, ${ }^{1,2,3}$ Mara Campeol, $, 1,3$ Federica Gentili, ${ }^{3}$ Angela Favaro, ${ }^{1,2,3}$ Carla Cremonese ${ }^{3}$ \\ ${ }^{1}$ Neurosciences Department, University of Padua; ${ }^{2}$ Neuroscience Center, University of Padua; ${ }^{3}$ Padua University Hospital, Psychiatry \\ Unit, Padua, Italy
}

\begin{abstract}
Outreaching activities decrease prognostic accuracy of at-risk mental state defining tools, over-attracting subjects who are not at increased risk of mental illness. The setting was a mental illness primary indicated prevention outpatients service embedded within the Psychiatry Unit of Padua University Hospital, Italy. Help-seeking patients accessing the service between January 2018 and December 2018 were evaluated with validated tools assessing functioning, at-risk mental state, schizotypal personality features, depressive and anxious symptoms, together with medical and family history collection. The primary outcome was the prevalence of drop in functioning at presentation according to the Social and Occupational Functioning Assessment Scale (SOFAS). Secondary outcomes were diagnoses according to DSM- 5 criteria and meeting criteria for at-risk mental state. Fifty-nine patients accessed the service, mean age was 18.8 (2.12) years old, 54.2\% were females. Virtually all subjects (97.7\%) had a drop in functioning. Baseline primary diagnoses were depressive episode in $33 \%$, anxiety disorder in $21 \%$, personality disorder in $17 \%$, adjustment disorder $9 \%$, conduct disorder 7\%, schizophrenia spectrum disorder 5\%, bipolar disorder 5\%, eating disorder in $1.7 \%$, dissociative disorder $1.7 \%$. Overall, 59.1\% met at-risk mental state criteria. Lower functioning was associated with anxious symptoms ( $\mathrm{p}=0.031)$, a family history of mental illness $(p=0.045)$ and of suicide $(p=0.042)$, and schizotypal personality traits $(p=0.036)$. Subjects accessing a prevention service embedded within the mental health department already present a trans-diagnostic drop in functioning, mainly due to a non-psychotic mental disorder, with at-risk mental state in one patient out of two, and schizophrenia or bipolar disorder already present in only $10 \%$ of subjects. Prevention service within mental health facility setting appears to properly detect subjects in need of treatment with a drop in functioning, at risk of developing severe mental illness, without any outreaching activity in the general population.
\end{abstract}

Key words: Prevention; early intervention; help-seeking; appropriateness; need for treatment; pathway to care.

Correspondence: Marco Solmi, Neurosciences Department, University of Padua, Via Giustiniani 3, Padua, 35100, Italy. Tel.: +39.0498213831.

E-mail: marco.solmi@unipd.it

Citation: Solmi, M., Campeol, M., Gentili, F., Favaro, A., \& Cremonese, C. (2020). Clinical presentation and need for treatment of a cohort of subjects accessing to a mental illness prevention service. Research in Psychotherapy: Psychopathology, Process and Outcome, 23(1), 24-32. doi: 10.4081/ripppo.2020.434

Conflict of interest: The authors declare no potential conflict of interest.

Received for publication: 17 October 2019.

Accepted for publication: 4 March 2020

This work is licensed under a Creative Commons Attribution NonCommercial 4.0 License (CC BY-NC 4.0).

${ }^{\circ}$ Copyright: the Author(s), 2020

Licensee PAGEPress, Italy

Research in Psychotherapy:

Psychopathology, Process and Outcome 2020; 23:24-32

doi:10.4081/ripppo.2020.434

\section{Introduction}

Age of onset of mental illness is in adolescence or young adulthood the latest, (Birrell, Newton, Teesson, Tonks, \& Slade, 2015; Goodwin \& Hamilton, 2002; Hudson, Hiripi, Pope, \& Kessler, 2007; Thorup et al., 2007) if not in childhood (neurodevelopmental disorders).(Atladottir et al., 2014) Duration of untreated illness is one of the main determinants of long-term outcome in subjects suffering from mental illness, (Compton, et al., 2011; Compton, Gordon, Weiss, \& Walker, 2011; Ghio, Gotelli, Marcenaro, Amore, \& Natta, 2014; Hung, Liu, \& Yang, 2017; Medeiros, Senço, Lafer, \& Almeida, 2016; Penttilä, Jaäskeläinen, Hirvonen, Isohanni, \& Miettunen, 2014) yet it remains, for the vast majority of mental disorders, too long and generally far from meeting clinical recommendations. A provocative editorial has stated that psychogeriatrics starts right after adolescence, suggesting that the current worldwide mental health services organization splitting adult (age $\geq 18$ ) from childhood/adolescence psychiatry fails to prevent or to intervene early in subjects with mental illness.(Parellada, 2013) Hence, mental illness pre- 
vention services have been and are being set up in several contexts, (Fusar-Poli et al., 2018; Fusar-Poli, Davies et al., 2019; Fusar-Poli, Estradé et al., 2019; Fusar-Poli, Oliver et al., 2019; McGorry, Hartmann, Spooner, \& Nelson, 2018) with age intake threshold often below age 18 .

However, it has also been shown that detection rates of subjects later developing psychosis is as low as 5\%.(van Os \& Guloksuz, 2017) Moreover, the transition rates (from at-risk state to psychosis) depend on several factors, with lower functioning and referrals from clinical contexts increasing the risk of transition to psychosis when meeting Ultra-High Risk (UHR+) criteria. Any attempt in improving detection rates through outreaching activities in the general population ultimately results in a dramatic loss of prognostic accuracy of the state-of-theart UHR definition tools(Fusar-Poli et al., 2016) (such as Comprehensive Assessment of At-Risk Mental State), (Yung et al., 2005) as opposed to referrals from medical or psychiatric clinical contexts, as well as low functioning which confer a pre-test risk enrichment, optimizing tools' prognostic accuracy.

Hence, setting a mental illness prevention service within the context of a larger hospital, and specifically of a psychiatry department, without any outreaching activity, and solely relying on referrals from clinical contexts, might be expected to select subjects with adequate pre-test risk enrichment. Also, not limiting the target population to those subjects meeting UHR criteria might allow those individuals with different from UHR clinical profiles (which equally results in a drop in functioning) to receive an early assessment and eventual needs-based treatment.

The present work aims to describe the functioning level and eventual psychiatric disorders in subjects referring to a mental illness prevention service within a hospital, and specifically within a mental health department which did not engage in any outreaching activity.

\section{Methods}

\section{Setting}

The setting was a mental illness primary indicated prevention outpatients service embedded within the Psychiatry Unit of Padua University Hospital. The age intake threshold was 14. No outreaching activity in the general population was made, and all patients were referred by mental health specialists, emergency department, or general practitioners. Help-seeking patients accessing the service between January 2018 and December 2018 were evaluated with validated tools measuring functioning, atrisk mental state, schizotypal personality features, depressive and anxious symptoms, together with medical and family history collection.

\section{Clinical assessment}

More specifically, the Social and Occupational Functioning Assessment Scale (SOFAS)(Goldman, Skodol, \&
Lave, 1992) was used to measure functioning. SOFAS evaluates four areas of functioning, namely social relevant activities, including work and academic performance, social and personal relationships, self-care, disturbing and aggressive behaviors. Functioning is scored on a continuum from 0 (lowest) to 100 (highest), where range 90100 and 80-90 identify people with greater functioning than the general population, 70 as a threshold for mild difficulties, 70 to 30 indicating moderate difficulties and score lower than 30 identifying subjects in need for support or supervision. Functioning was also assessed with the Health of the Nation Outcome Scale (HoNOS) eHealth of the Nation Outcome Scale for Children and Adolescents (HONOSCA). These multidimensional scales focus on daily functioning impairment due to symptoms. The adult version (HoNOS) consists of 12 items, while the adolescent one (HoNOS-CA) consists of 13 items. (Gowers et al., 1999; Pirkis et al., 2005; Wing et al., 1998) each item score goes from 0 (no problems at all), 1 (mild problem without the need of any specific action), 2 (issue of mild intensity but still relevant to the person functioning), 3 (moderate issue with the need for treatment) to 4 (serious to very severe problem). HoNOS and HoNOS-CA were the only instruments differing between adults and adolescents.

Global score can be split up into four subscales evaluating functioning impairment related to psychiatric symptoms, such as depression, anxiety, hallucinations, and concerns, related to impairment in global basic functions, as psychomotor, cognitive or physical limitations, related to behavior including violence both against self and the others, and finally related to social and environmental issues (housing problem, unemployment or financial difficulties, interpersonal troubles, and lack of social support). Schizotypal features were assessed with the Schizotypal Personality Questionnaire Brief Version (SPQ-B), already widely applied both in general and clinical population (Fonseca-Pedrero, Lemos-Giráldez, Paino, Sierra-Baigrie, \& Muñiz, 2012; Fonseca-Pedrero, PaínoPiñeiro, Lemos-Giráldez, Villazón-García, \& Muñiz, 2009) with a cut-off score of 17 indicating the presence of schizotypal personality traits. Patients underwent the Comprehensive Assessment of At-Risk Mental States (CAARMS) (Yung et al., 2005) to assess whether they met the criteria for ultra-high risk (UHR) state. CAARMS is a semi-structured interview investigating seven psychopathological areas through dedicated domains: positive symptoms, cognitive functioning, affectivity, negative symptoms, behavioral changing, motility and experience of body, and general psychopathology. Positive symptoms are investigated with a specific focus on unusual thought content, not bizarre ideas, perceptive anomalies, and disorganized speech. Positive symptoms intensity and frequency, together with a drop in functioning defines whether a subject meets or does not meet UHR criteria. UHR criteria and the wider framework of the staging of 
schizophrenia we refer to in this work are reported in Table 1. Depressive symptoms were assessed with the Hamilton Rating Scale for Depression (HAM-D), (Hamilton, 1960) and anxious symptoms with the Hamilton Rating Scale for Anxiety (HAM-A).(Hamilton, 1959) Diagnoses were formulated according to DSM-5 criteria, utilizing a clinical interview performed by a psychiatrist.

\section{History collection}

Clinical and family history were collected including family history for mental illness and suicide, perinatal complications, previous contacts with public mental health services, and ongoing psychopharmacological therapy. Substance use was also investigated, with special regards to cannabis. Some self-reported information was also collected, namely non-specific physical symptoms, as headache, asthenia, and gastrointestinal distress, along with stressful life events.

\section{Primary and secondary outcomes}

The primary outcome was a drop in functioning defined as SOFAS below 70 , or a loss of more than $30 \%$ in

Table 1. Staging model of severe mental illness, and specific criteria for ultra-high risk for psychosis.

\begin{tabular}{|c|c|c|c|}
\hline Stage & Definition & Target populations and referral sources & Potential interventions \\
\hline 0 & $\begin{array}{l}\text { Increased risk of psychotic or severe } \\
\text { mood disorder. } \\
\text { No symptoms currently }\end{array}$ & First-degree teenage relatives of probands & $\begin{array}{l}\text { Improved mental health literacy } \\
\text { Family education, drug education } \\
\text { Brief cognitive skills training }\end{array}$ \\
\hline $1 \mathrm{a}$ & $\begin{array}{l}\text { Mild or non-specific symptoms } \\
\text { (including neurocognitive deficits) of } \\
\text { psychosis or severe mood disorder. } \\
\text { Mild functional change or decline }\end{array}$ & $\begin{array}{l}\text { Screening of teenage populations; } \\
\text { Referral by: primary care physicians; } \\
\text { school counselors }\end{array}$ & $\begin{array}{l}\text { Formal mental health literacy } \\
\text { Family psychoeducation, formal CBT } \\
\text { Active substance misuse reduction }\end{array}$ \\
\hline $1 \mathrm{~b}$ & $\begin{array}{l}\text { Ultra-high risk: moderate but } \\
\text { subthreshold symptoms, with moderate } \\
\text { neurocognitive changes and functional } \\
\text { decline to caseness }(\mathrm{GAF},<70)\end{array}$ & $\begin{array}{l}\text { Referral by: educational agencies; primary care } \\
\text { physicians; emergency departments; welfare } \\
\text { agencies }\end{array}$ & $\begin{array}{l}\text { Family psychoeducation, formal CBT } \\
\text { Active substance misuse reduction } \\
\text { Omega-3 fatty acids } \\
\text { Atypical antipsychotic agents } \\
\text { Antidepressant agents or mood stabilizers }\end{array}$ \\
\hline 2 & $\begin{array}{l}\text { First episode of psychotic or severe } \\
\text { mood disorder } \\
\text { Full threshold disorder with moderate } \\
\text { to severe symptoms, neurocognitive } \\
\text { deficits and functional decline } \\
\text { (GAF, 30-50) }\end{array}$ & $\begin{array}{l}\text { Referral by: primary care physicians; emergency } \\
\text { departments; welfare agencies; specialist care } \\
\text { agencies; drug and alcohol services }\end{array}$ & $\begin{array}{l}\text { Family psychoeducation, formal CBT } \\
\text { Active substance misuse reduction } \\
\text { Atypical antipsychotic agents } \\
\text { Antidepressant agents or mood stabilizers } \\
\text { Vocational rehabilitation }\end{array}$ \\
\hline $3 a$ & $\begin{array}{l}\text { Incomplete remission from the first } \\
\text { episode of care }\end{array}$ & $\begin{array}{l}\text { Primary and specialist care services } \\
\text { on medical and psychosocial strategies to achieve } \\
\text { full remission }\end{array}$ & As for Stage 2, but with additional emphasis \\
\hline
\end{tabular}

Recurrence or relapse of psychotic or
mood disorder, which stabilizes with

Primary and specialist care services

As for Stage 3a, but with additional emphasis treatment at a GAF level, or with residual symptoms or neurocognition "searly warning signs" below the best level achieved after remission from the first episode

\begin{tabular}{|c|c|c|c|}
\hline $3 \mathrm{c}$ & $\begin{array}{l}\text { Multiple relapses provided worsening } \\
\text { in clinical extent and impact of illness } \\
\text { is objectively present }\end{array}$ & Specialist care services & $\begin{array}{l}\text { As for Stage } 3 b \text {, but with emphasis on } \\
\text { long-term stabilization }\end{array}$ \\
\hline 4 & $\begin{array}{l}\text { Severe, persistent or unremitting illness } \\
\text { as judged by symptoms, neurocognition } \\
\text { and disability criteria }\end{array}$ & Specialized care services & $\begin{array}{l}\text { As for Stage } 3 \mathrm{c} \text {, but with emphasis on } \\
\text { clozapine, other tertiary treatments, and social } \\
\text { participation despite ongoing disability }\end{array}$ \\
\hline
\end{tabular}

UHR criteria

Functional Criterion Help-seeking young adults with a recent significant decline in psychosocial functioning or chronic low functioning during the previous year.

Plus one or more of the following clinical criteria:

\begin{tabular}{ll} 
APS & $\begin{array}{l}\text { Presence of subthreshold, positive symptoms during the past yearIdeas of reference, odd beliefs or magical thinking, including } \\
\text { ideas of grandiosity, Paranoid ideation, Unusual perceptual experiences, odd thinking and speech. Subgroups:2A- sub-threshold } \\
\text { intensity2B- sub-threshold frequency }\end{array}$ \\
\hline BLIPS & $\begin{array}{l}\text { Presence of episodes of frank psychotic symptoms that have not lasted longer than a week and have spontaneously abated } \\
\text { (that is, without treatment). }\end{array}$ \\
\hline GRFD & Presence of a Genetic risk Factor (family history of psychosis; schizotypal personality disorder of person)
\end{tabular}

The staging model adapted from McGorry et al. 2006. UHR risk criteria adapted from Yung et al. (2005); APS: Attenuated Psychotic Symptoms; BLIPS: Brief Limited Intermittent Psychotic Symptoms; GRFD: Combination of Genetic Risk and Functional Decline. 
SOFAS score in the last 12 months. Secondary outcomes were prevalence of primary diagnoses according to DSM5 criteria, and meeting UHR criteria.

\section{Statistical Analysis}

Frequency and mean values of primary and secondary outcomes were simply calculated with descriptive statistics. The normality of variables distribution was assessed with the Shapiro-Wilk test. Associations between clinical factors and primary outcome (codified as continuous scores) were assessed with Student's t-test (categorical factors) or Pearson correlation (continuous factors) in case of normal distribution, or with Mann-Whitney's U or ANOVA (categorical factors) or Spearman's rho (continuous factors) in case of non-normal distribution. A chisquared test was used to compare the distribution of primary and secondary outcomes (codified as categorical values) across categorical factors. Statistical analysis has been performed with Jamovi open software for Windows.

\section{Results}

\section{Characteristics of the included sample, primary and secondary outcomes}

Demographic characteristics and frequency of primary and secondary outcomes are reported in Table 2. Fiftynine adolescents and young adults aged 15-24 accessed the prevention service embedded within Padua University Hospital, Psychiatry Unit. Overall mean age was 18.8 (2.12) years old, $54.2 \%$ were females.

A drop in functioning as measured with SOFAS below 50 was present in $32.6 \%$, and below 70 in $97.7 \%$, and mean SOFAS score was 56.5 (SD 11.3). The mean HONOS(-CA) score was 15.7 (SD 6.3). Patients were affected by a depressive episode ( $\mathrm{n}=19 ; 32.7 \%)$, anxiety disorder $(\mathrm{n}=19 ; 32.7 \%)$, personality disorder $(\mathrm{n}=10 ; 17.3 \%$, , conduct disorder $(\mathrm{n}=4 ; 6.9 \%)$, schizophrenia $(\mathrm{n}=3 ; 5.2 \%)$, bipolar disorder $(n=3 ; 5.2 \%)$. Overall, $59.1 \%$ met UHR criteria. Specifically, subjects at UHR had Attenuated Psychotic Symptoms (77\%), Genetic Risk and Deterioration syndrome plus Attenuated Psychotic Symptoms (19\%), and Brief Limited Intermittent Psychotic Symptoms plus Attenuated Psychotic Symptoms (4\%). UHR criteria were met most frequently in "not bizarre ideas" (61\%) and unusual thought content (41.5\%). Virtually all patients had at least mild anxious symptoms (96.9\%), and $85.3 \%$ had at least mild depressive symptoms. SPQ-B was positive for schizotypal personality traits in $13.6 \%$.

\section{Characteristics associated with primary and secondary outcomes}

Considering SOFAS, no correlation showed up with family history of psychiatric illness and family history of suicide, nor perinatal complications. Age, first degree rel- atives with psychiatric illness, previous contacts with public mental health services, ongoing psychopharmacological therapy, and substance misuse (cannabis) were not statistically significantly associated with functioning neither. Notably, considering SOFAS, functioning did not differ between UHR+ and UHR - subjects, across diagnoses, nor it correlated with depressive and anxious symptoms.

Considering HONOS and HONOS-CA, a family history of psychiatric illness and family history of suicide showed to be associated with a drop in functioning, when considering specific subscales (Table 4, Table 5). More in detail, second-degree family history of psychiatric illness was associated with the HoNOS subscale $(\mathrm{p}=0.045)$, family history of suicide with Symptoms HoNOS subscales $(\mathrm{p}=0.042)$, and schizotypal personality with social HoNOS subscale $(\mathrm{p}=0.036)$. Also, anxiety symptoms correlated with symptoms of HoNOS-CA $(r=0.576, p=0.031)$. On the other hand, age, first degree relatives with psychiatric illness, previous contacts with public mental health services, ongoing psychopharmacological therapy, and substance misuse (cannabis) were not statistically significantly associated with functioning. HONOS and HONOS-CA did not differ between UHR+ and UHR- subjects even when specific subscales were considered. HONOS and HONOS-CA differed/did not differ across diagnoses neither and did not correlate with depressive or anxiety symptoms.

Associations among clinical factors and functioning are reported in Table 3 and Table 4.

No association emerged between functioning and C-section (Table 6).

\section{Discussion}

This study shows that a primary indicated prevention service embedded in a mental health unit within a wider clinical context (general hospital) properly detects young help-seeking subjects who do have a drop in functioning, but who have not developed schizophrenia spectrum disorder nor bipolar disorder yet.

Prevention is still in its infancy in psychiatry. Duration of untreated illness has shown to be far from meeting duration criteria in several mental disorders, including depressive disorder, (Hung, Yu, Liu, Wu, \& Yang, 2015) bipolar disorder, (Dagani et al., 2017; van Meter, Burke, Youngstrom, Faedda, \& Correll, 2016) schizophrenia, (Compton et al., 2011) obsessive-compulsive disorder, (Albert et al., 2019) anxiety disorders, (Benatti et al., 2016) among others.(Kisely, Scott, Denney, \& Simon, 2006) Such delay in detecting subjects with mental illness onset can be also due to the artificial splitting of mental health services between age under and greater than 18. As already suggested, psychogeriatrics start right after adolescence, (Parellada, 2013) and early intervention, hence prevention services (even more) should not set any age intake threshold. As shown by the present data, subjects start suffering from early symptoms of non-psychotic 
Table 2. Demographic and clinical characteristics of the included sample.

\begin{tabular}{|c|c|c|}
\hline Variable & Mean & SD, $\%$ \\
\hline Female & & $54.2 \%$ \\
\hline Age & 18.8 & 2.12 \\
\hline Family history for mental illness, first degree & & $50.9 \%$ \\
\hline Family history for mental illness, second degree & & $47.3 \%$ \\
\hline Family history of suicide & & $12.7 \%$ \\
\hline Perinatal complications: $\mathrm{C}$ section & & $22.0 \%$ \\
\hline Previous contacts with mental health services & & $11.8 \%$ \\
\hline Ongoing psychopharmacological therapy & & $37.3 \%$ \\
\hline Substance Use (cannabis) & & $28.1 \%$ \\
\hline General non-specific physical symptoms, self-report & & $87.5 \%$ \\
\hline Gastrointestinal symptoms, self-report & & $30.4 \%$ \\
\hline Stressful life events, self-report: traumatic relationship breakup & & $62.5 \%$ \\
\hline SOFAS & Mean 56.5 & SD 11.3 \\
\hline HONOS (global score) & Mean 13.4 & SD 5.7 \\
\hline HoNOS Behavior subscale & Mean 2.52 & SD 2.56 \\
\hline HONOS Impairment subscale & 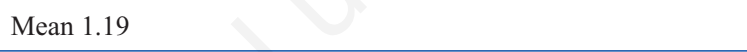 & SD 1.47 \\
\hline HoNOS Symptom subscale & Mean 2.57 & SD 1.69 \\
\hline HoNOS Social subscale & Mean 4.76 & SD 3.51 \\
\hline HONOS-CA (global score) & Mean 15.7 & SD 6.3 \\
\hline HONOS-CA Behavior subscale & Mean 3.52 & SD 2.10 \\
\hline HONOS-CA Impairment subscale & Mean 1.44 & SD 1.53 \\
\hline HONOS-CA Symptom subscale & Mean 4.32 & SD 2.30 \\
\hline HONOS-CA Social subscale & Mean 6.40 & SD 3.25 \\
\hline HAM-D & $\begin{array}{l}\text { Mild } \\
\text { Moderate } \\
\text { Severe }\end{array}$ & $\begin{array}{l}50.0 \% \\
35.3 \% \\
14.7 \% \\
\end{array}$ \\
\hline HAM-A & $\begin{array}{l}\text { Mild }(<17) \\
\text { Moderate }(17-24) \\
\text { Moderate to Severe }(24-31) \\
\text { Severe }(<31)\end{array}$ & $\begin{array}{c}65.6 \% \\
21.9 \% \\
6.3 \% \\
3.1 \% \\
\end{array}$ \\
\hline SPQ-B & Schizotypal features & $13.6 \%$ \\
\hline \multicolumn{3}{|l|}{ Primary and secondary outcomes } \\
\hline Drop in functioning $(\mathrm{n}=43)$ & $\begin{array}{l}\text { SOFAS }<50 \\
\text { SOFAS }<70 \\
\text { SOFAS drop }>30 \% \text { in } 12 \text { months }\end{array}$ & $\begin{array}{l}32.6 \% \\
97.7 \% \\
83.7 \% \\
\end{array}$ \\
\hline Primary diagnoses & $\begin{array}{l}\text { Depressive episode, current, mild (F32.0) } \\
\text { Anxiety disorder, NAS (F43.20) } \\
\text { Personality disorder (90\% Avoidant personality disorder (F60.6)) } \\
\text { Conduct disorder (F91.9) } \\
\text { Schizophrenia (F20.9) } \\
\text { Bipolar disorder, NAS (F31.9) }\end{array}$ & $\begin{array}{c}32.7 \% \\
32.7 \% \\
17.3 \% \\
6.9 \% \\
5.2 \% \\
5.2 \% \\
\end{array}$ \\
\hline UHR & $\begin{array}{l}\text { APS } \\
\text { GRFD+APS } \\
\text { BLIPS+APS }\end{array}$ & $\begin{array}{c}77 \% \\
19 \% \\
4 \%\end{array}$ \\
\hline
\end{tabular}

SOFAS: Social and Occupational Functioning Assessment Scale. HONOS: Health of the Nation Outcome Scale; HONOS-CA: Health of the Nation Outcome Scale for Children and Adolescents; HAM-D: Hamilton Rating Scale for Depression; HAM-A: Hamilton Rating Scale for Anxiety; SPQ-B: Schizotypal Personality Questionnaire Brief Version; UHR: Ultra-High-Risk; APS: Attenuated Psychotic Symptoms; BLIPS: Brief Limited Intermittent Psychotic Symptoms; GRFD: Combination of Genetic Risk and Functional Decline. 
mental illness well before age 18 , and all of them already have a drop in functioning when accessing prevention service. Also, the present data support the appropriateness across prevention services of a soft entry point(McGorry et al., 2018) rather than a stricter inclusion criteria focusing on UHR status only, (Yung et al., 2005) given that functioning is compromised across all diagnoses, and across both UHR+ and UHR- subjects, and given that no significant difference in terms of functioning emerged across such groups. Such a trans-diagnostic drop in functioning may be because among all subjects with anxiety disorders, reasonably only a small portion makes it to the clinical attention, leaving out subjects with the subclinical symptom, possibly seeking help outside of the clinical network of public health services. Indeed, the clinical setting and the absence of any outreaching activity of the service has both advantages and disadvantages. The advantages are related to the (mental health) clinical environment acting as a filter including only help-seeking and more severe cases who do have an increased risk of developing psychosis or bipolar disorder, for instance, (Fusar-Poli et al., 2016; Fusar-Poli, Sullivan, Shah, \& Uhlhaas, 2019; Fusar-Poli, Werbeloff et al., 2019; van Meter et al., 2016) hence minimizing the risk to treat subjects whose symptoms might have self-remitted later without any intervention, thus minimizing the risk of any harm potentially related to psychotherapeutic or psychopharmacologic agents. The disadvantages are however that setting the prevention services within a clinical context might act as a barrier to those subjects with less committed help-seeking attitude, allowing also stigma(Green,

Table 3. Global functioning is homogenously compromised in help-seeking subjects aged 15 to 24 .

\begin{tabular}{llll}
\hline SOFAS continuous score and categorical factors & & & \\
\hline Gender & $\mathrm{U}=234$ & Male 55.4 (13.3) vs Female 57.6 (9.39) & $\mathrm{p}=0.858$ \\
\hline Family history of suicide & $\mathrm{U}=85$ & $53.6(8.02)$ vs $57.0(12.3)$ & $\mathrm{p}=0.280$ \\
\hline Family history of mental illness, first and second degree & $\mathrm{U}=164$ & $55.5(11.5)$ vs 57.9 (11.9) & $\mathrm{p}=0.620$ \\
\hline UHR & $\mathrm{U}=159$ & $55.5(10.8)$ vs 57.7 (13) & $\mathrm{p}=0.332$ \\
\hline
\end{tabular}

SOFAS continuous score and continuous factors

\begin{tabular}{llll}
\hline Age & - & rho $=-0.068$ & $p=0.660$ \\
\hline HAM-D & - & rho $=-0.087$ & $p=0.631$ \\
\hline HAM-A & - & rho $=0.027$ & $p=0.887$ \\
\hline
\end{tabular}

HONOS continuous and categorical factors

\begin{tabular}{llll}
\hline Gender & $\mathrm{t}=0.357$ & Male 12.9 (4.82) vs Female 13.8 (6.69) & $\mathrm{p}=0.725$ \\
Family history of suicide & $\mathrm{t}=-0.973$ & $16(1.41)$ vs 12.3 (5.24) & $\mathrm{p}=0.344$ \\
\hline Family history of mental illness, first and second degree & $\mathrm{t}=-0.020$ & $13.4(6.38)$ vs 13.3 (2.08) & $\mathrm{p}=0.984$ \\
\hline UHR & $\mathrm{t}=-0.163$ & $12.7(5.27)$ vs 13.2 (5.67) & $\mathrm{p}=0.873$ \\
\hline
\end{tabular}

HONOS categorical and continuous factors

\begin{tabular}{llll}
\hline Age & - & rho value $=-0.066$ & $p=0.778$ \\
HAM-D & - & $r=-0.068$ & $p=0.811$ \\
\hline HAM-A & - & $r=-0.284$ & $p=0.325$
\end{tabular}

HONOS-CA continuous and categorical factors

\begin{tabular}{llll}
\hline Gender & $\mathrm{t}=0.473$ & Male 15.0 (7.01) vs Female 16.2 (5.82) & $\mathrm{p}=0.640$ \\
\hline Family history of suicide & $\mathrm{t}=1.24$ & $11.7(7.51)$ vs 16.4 (5.99) & $\mathrm{p}=0.228$ \\
\hline Family history of mental illness & $\mathrm{t}=-0.551$ & $16.5(6.51)$ vs 15.0 (5.76) & $\mathrm{p}=0.587$ \\
\hline UHR & $\mathrm{t}=0.194$ & $15.8(5.41)$ vs $15.1(8.3)$ & $\mathrm{p}=0.848$ \\
\hline HONOS-CA categorical and continuous factors & & & $\mathrm{p}=0.294$ \\
\hline Age & - & $\mathrm{rho}=0.218$ & $\mathrm{p}=0.299$ \\
\hline HAM-D & - & $\mathrm{r}=0.299$ & $\mathrm{p}=0.160$ \\
\hline HAM-A & - & $\mathrm{r}=0.397$ & \\
\hline
\end{tabular}

SOFAS: Social and Occupational Functioning Assessment Scale; HONOS: Health of the Nation Outcome Scale; HONOS-CA: Health of the Nation Outcome Scale for Children and Adolescents; HAM-D: Hamilton Rating Scale for Depression; HAM-A: Hamilton Rating Scale for Anxiety; SPQ-B: Schizotypal Personality Questionnaire Brief Version; UHR: Ultra-High-Risk. U= MannWhitney'U; t=Student's t. 
Hunt, \& Stain, 2012; Kamaradova et al., 2016) to delay referral to professional mental health context, ultimately prolonging the duration of untreated illness. Further studies should assess whether keeping prevention services within the clinical context in the local context where the present study is set is an effective approach in detecting only subjects actually at increased risk of developing schizophrenia or bipolar disorder or recurrent major depressive disorder, and at the same time in detecting a sub- stantial proportion of those who later develop the conditions, also thanks to a softer entry point which might be a considerable difference from the criticized UHR paradigm-based services.(van Os \& Guloksuz, 2017).

The presence of only a few positive correlations suggests a homogenous distribution of functioning impairment across young help-seeking subjects included in the present study. There is the need for a comprehensive diagnostic assessment that has to go beyond the drop in

Table 4. Mean comparison between HONOS and HONOS-CA, global score and subscales with regards to the family history of psychiatric illness.

\begin{tabular}{|c|c|c|c|c|c|c|c|}
\hline HoNOS & & Test & History of psychiatric illness & No history of psychiatric illness & Stat & df & $\mathbf{p}$ \\
\hline \multirow[t]{5}{*}{ HoNOS } & Tot & $\mathrm{t}$ & $12.1 \pm 6.0$ & $15.4 \pm 5.6$ & 1.240 & 18.0 & 0.231 \\
\hline & SYM & $\mathrm{t}$ & $2.17 \pm 1.80$ & $3.25 \pm 1.49$ & 1.408 & 18.0 & 0.176 \\
\hline & Soc & $\mathrm{t}$ & $5.00 \pm 4.61$ & $4.50 \pm 1.20$ & -0.298 & 18.0 & 0.769 \\
\hline & Beh & $\mathrm{U}$ & $1.58 \pm 1.78$ & $3.75 \pm 3.20$ & 22.0 & - & 0.045 \\
\hline & $\operatorname{Imp}$ & $\mathrm{U}$ & $0.83 \pm 1.19$ & $1.75 \pm 1.83$ & 34.5 & - & 0.289 \\
\hline \multirow[t]{5}{*}{ HoNOS-CA } & Tot & $\mathrm{t}$ & $17.0 \pm 7.1$ & $14.7 \pm 6.0$ & -0.843 & 22.0 & 0.408 \\
\hline & SYM & $\mathrm{t}$ & $4.63 \pm 2.45$ & $4.06 \pm 2.32$ & -0.550 & 22.0 & 0.588 \\
\hline & Soc & $\mathrm{t}$ & $6.88 \pm 4.05$ & $6.00 \pm 2.92$ & -0.608 & 22.0 & 0.549 \\
\hline & Beh & $\mathrm{U}$ & $3.25 \pm 1.04$ & $3.63 \pm 2.55$ & 60.5 & - & 0.852 \\
\hline & $\operatorname{Imp}$ & $\mathrm{U}$ & $2.50 \pm 1.93$ & $0.87 \pm 1.02$ & 33.0 & - & 0.051 \\
\hline
\end{tabular}

HONOS: Health of the Nation Outcome Scale; HONOS-CA: Health of the Nation Outcome Scale for Children and Adolescents; Sym: symptoms subscale; Soc: social subscale; Beh: Behavior subscale; Imp: Impairment subscale. U= Mann-Whitney'U; t=Student's t.

Table 5. Mean comparison between HONOS and HONOS-CA, global score and subscales with regards to the family history of suicide.

\begin{tabular}{|c|c|c|c|c|c|c|c|}
\hline \multicolumn{2}{|l|}{ HoNOS } & \multirow{2}{*}{$\begin{array}{l}\text { Test } \\
t\end{array}$} & \multirow{2}{*}{$\begin{array}{l}\text { Family history of suicide } \\
16.0 \pm 1.4\end{array}$} & \multirow{2}{*}{$\begin{array}{l}\text { No family history of suicide } \\
12.3 \pm 5.2\end{array}$} & \multirow{2}{*}{$\begin{array}{l}\text { Stat } \\
-0.973\end{array}$} & \multirow{2}{*}{$\begin{array}{l}\text { df } \\
17.0\end{array}$} & \multirow{2}{*}{$\begin{array}{l}\mathbf{p} \\
0.344\end{array}$} \\
\hline HoNOS & Tot & & & & & & \\
\hline & Sym & $\mathrm{t}$ & $5.00 \pm 2.83$ & $2.35 \pm 1.50$ & -2.204 & 17.0 & 0.042 \\
\hline & Soc & $\mathrm{t}$ & $9.50 \pm 3.54$ & $4.18 \pm 3.36$ & -2.114 & 17.0 & 0.050 \\
\hline & Beh & $\mathrm{U}$ & $0.00 \pm 0.00$ & $2.24 \pm 1.64$ & 3.00 & - & 0.067 \\
\hline & $\operatorname{Imp}$ & $\mathrm{U}$ & $0.50 \pm 0.71$ & $1.06 \pm 1.30$ & 14.00 & - & 0.723 \\
\hline \multirow{5}{*}{ HoNOS-CA } & Tot & $\mathrm{t}$ & $11.7 \pm 7.5$ & $16.4 \pm 6.0$ & 1.242 & 21.0 & 0.228 \\
\hline & Sym & $\mathrm{t}$ & $2.67 \pm 0.58$ & $4.70 \pm 2.23$ & 1.545 & 21.0 & 0.137 \\
\hline & Soc & $\mathrm{t}$ & $5.00 \pm 4.36$ & $6.70 \pm 3.10$ & 0.848 & 21.0 & 0.406 \\
\hline & Beh & $\mathrm{U}$ & $2.67 \pm 2.08$ & $3.65 \pm 2.23$ & 22.00 & - & 0.486 \\
\hline & $\operatorname{Imp}$ & $\mathrm{U}$ & $1.00 \pm 1.73$ & $1.50 \pm 1.61$ & 22.50 & - & 0.505 \\
\hline
\end{tabular}

HONOS: Health of the Nation Outcome Scale; HONOS-CA: Health of the Nation Outcome Scale for Children and Adolescents; Sym: symptoms subscale; Soc: social subscale; Beh: Behavior subscale; Imp: Impairment subscale.

Table 6. Mean comparison between HONOS and HONOS-CA, global score and subscales, with regards to C-section at birth.

\begin{tabular}{|c|c|c|c|c|c|c|c|}
\hline HoNOS & & Test & C-section & No C-section & Stat & df & $\mathbf{p}$ \\
\hline \multirow[t]{5}{*}{ HoNOS } & Tot & $\mathrm{t}$ & $14.7 \pm 7.2$ & $11.6 \pm 4.6$ & -0.9690 & 15.0 & 0.348 \\
\hline & Sym & $\mathrm{t}$ & $2.67 \pm 0.58$ & $2.79 \pm 2.01$ & 0.0995 & 15.0 & 0.922 \\
\hline & Soc & $\mathrm{t}$ & $7.00 \pm 6.93$ & $4.07 \pm 3.05$ & -1.210 & 15.0 & 0.245 \\
\hline & Beh & $\mathrm{U}$ & $1.33 \pm 2.31$ & $2.00 \pm 1.71$ & 15.5 & - & 0.520 \\
\hline & $\operatorname{Imp}$ & $\mathrm{U}$ & $1.33 \pm 1.53$ & $0.643 \pm 0.929$ & 14.5 & - & 0.406 \\
\hline \multirow[t]{5}{*}{ HoNOS-CA } & Tot & $\mathrm{t}$ & $19.8 \pm 7.2$ & $14.6 \pm 5.9$ & -1.601 & 17.0 & 0.128 \\
\hline & Sym & $\mathrm{t}$ & $6.40 \pm 2.19$ & $4.14 \pm 2.03$ & -2.092 & 17.0 & 0.052 \\
\hline & Soc & $\mathrm{t}$ & $7.40 \pm 3.36$ & $5.79 \pm 3.19$ & -0.9588 & 17.0 & 0.351 \\
\hline & Beh & $\mathrm{U}$ & $4.80 \pm 3.56$ & $3.14 \pm 1.75$ & 28.0 & - & 0.539 \\
\hline & $\operatorname{Imp}$ & $\mathrm{U}$ & $2.40 \pm 1.82$ & $1.21 \pm 1.19$ & 20.0 & - & 0.166 \\
\hline
\end{tabular}

HONOS: Health of the Nation Outcome Scale; HONOS-CA: Health of the Nation Outcome Scale for Children and Adolescents; Sym: symptoms subscale; Soc: social subscale; Beh: Behavior subscale; Imp: Impairment subscale.U= Mann-Whitney'U; t=Student's t. 
functioning in young help-seeking subjects, to detect diagnosis- or spectrum-specific clinical features to administer the proper treatment. Also, the lack of significant differences in functioning across different clinical features might be due to the non-specific nature of SOFAS or similar instrument, which calls for new instruments measuring functioning with a finer-grained approach compared with those available to date.

The present study has some strengths. First, it reports on a real-world setting where however validated scales have been applied, providing valid clinical measures Second, it shows that a prevention service embedded in a psychiatry unit within a University Hospital detects young subjects who have severe clinical pictures and who might have waited months or even years before accessing to adult mental health services. In this sense, the results of this study support the clinical appropriateness of such prevention service which fills a gap in the current mental health organization in Italy.

The study has several limitations. First, it has a crosssectional design and an estimate of the proportion of and factors associated with the transition to psychosis remains unstudied. Second, the sample size is relatively small and analyses may have been underpowered to detect significant associations between functioning and other clinical factors. Third, results are valid only for the local context, and any inference in different settings would require external replication.

In conclusion, prevention service within mental health facility setting appears to properly detect subjects in need of treatment with a drop in functioning, without outreaching activity in the general population. Padua prevention service detects help-seeking subjects with frequent age below 18 , in need of treatment for comorbid early depressive episodes, anxiety or personality disorders, who in around one case out of two also meet UHR criteria, who all have poor functioning.

\section{References}

Albert, U., Barbaro, F., Bramante, S., Rosso, G., De Ronchi, D., \& Maina, G. (2019). Duration of untreated illness and response to SRI treatment in Obsessive-Compulsive Disorder. European Psychiatry 58, 19-26. DOI: https://doi.org/10.1016/j.eurpsy.2019.01.017

Atladottir, H. O., Gyllenberg, D., Langridge, A., Sandin, S., Hansen, S. N., Leonard, H., (...) Parner, E. T. (2014). The increasing prevalence of reported diagnoses of childhood psychiatric disorders: a descriptive multinational comparison. European Child and Adolescent Psychiatry 24(2), 173-183. DOI: https://doi.org/10.1007/s00787-014-0553-8

Benatti, B., Camuri, G., Dell'Osso, B., Cremaschi, L., Sembira, E., Palazzo, C., (...) Altamura, A. C. (2016). Which factors influence onset and latency to treatment in generalized anxiety disorder, panic disorder, and obsessive-compulsive disorder? International Clinical Psychopharmacology 31(6), 347-352. DOI: https://doi.org/10.1097/YIC.0000000000000137

Birrell, L., Newton, N. C., Teesson, M., Tonks, Z., \& Slade, T.
(2015). Anxiety disorders and first alcohol use in the general population. Findings from a nationally representative sample. Journal of Anxiety Disorders 31, 108-113. DOI: https://doi.org/10.1016/j.janxdis.2015.02.008

Compton, M. T., Gordon, T. L., Goulding, S. M., Esterberg, M. L., Carter, T., Leiner, A. S., (...) Kaslow, N. J. (2011). PatientLevel Predictors and Clinical Correlates of Duration of Untreated Psychosis among Hospitalized First-Episode Patients. Journal of Clinical Psychiatry Vol. 72, pp. 225-232. DOI: https://doi.org/10.4088/JCP.09m05704yel

Compton, M. T., Gordon, T. L., Weiss, P. S., \& Walker, E. F. (2011). The 'doses' of initial, untreated hallucinations and delusions: A proof-of-concept study of enhanced predictors of first-episode symptomatology and functioning relative to duration of untreated psychosis. Journal of Clinical Psychiatry 72(11), 1487-1493. DOI: https://doi.org/10.4088/ JCP.09m05841yel

Dagani, J., Signorini, G., Nielssen, O., Bani, M., Pastore, A., Girolamo, G. De, \& Large, M. (2017). Meta-analysis of the Interval between the Onset and Management of Bipolar Disorder. Canadian Journal of Psychiatry Vol. 62, pp. 247-258. DOI: https://doi.org/10.1177/0706743716656607

Fonseca-Pedrero, E., Lemos-Giráldez, S., Paino, M., SierraBaigrie, S., \& Muñiz, J. (2012). Relationship between Schizotypal and Borderline Traits in College Students. The Spanish Journal of Psychology 15(1), 306-314. DOI: https://doi.org/10.5209/rev_sjop.2012.v15.n1.37337

Fonseca-Pedrero, E., Paíno-Piñeiro, M., Lemos-Giráldez, S., Villazón-García, Ú., \& Muñiz, J. (2009). Validation of the Schizotypal Personality Questionnaire-Brief Form in adolescents. Schizophrenia Research 111(1-3), 53-60. DOI: https://doi.org/10.1016/j.schres.2009.03.006

Fusar-Poli, P., Davies, C., Rutigliano, G., Stahl, D., Bonoldi, I., \& McGuire, P. (2019). Transdiagnostic individualized clinically based risk calculator for the detection of individuals at risk and the prediction of psychosis: Model refinement including nonlinear effects of age. Frontiers in Psychiatry 10(MAY). DOI: https://doi.org/10.3389/fpsyt.2019.00313

Fusar-Poli, P., Estradé, A., Spencer, T. J., Gupta, S., MurguiaAsensio, S., Eranti, S., (...) McGuire, P. (2019). Pan-London Network for Psychosis-Prevention (PNP). Frontiers in Psychiatry 10, 707. DOI: https://doi.org/10.3389/fpsyt.2019. 00707

Fusar-Poli, P., Oliver, D., Spada, G., Patel, R., Stewart, R., Dobson, R., \& McGuire, P. (2019). Real world implementation of a transdiagnostic risk calculator for the automatic detection of individuals at risk of psychosis in clinical routine: Study protocol. Frontiers in Psychiatry 10(MAR). DOI: https://doi.org/10.3389/fpsyt.2019.00109

Fusar-Poli, P, Palombini, E., Davies, C., Oliver, D., Bonoldi, I., Ramella-Cravaro, V., \& McGuire, P. (2018). Why transition risk to psychosis is not declining at the OASIS ultra high risk service: The hidden role of stable pretest risk enrichment. Schizophrenia Research 192, 385-390. DOI: https://doi.org/ 10.1016/j.schres.2017.06.015

Fusar-Poli, P., Schultze-Lutter, F., Cappucciati, M., Rutigliano, G., Bonoldi, I., Stahl, D., ... Mcguire, P. (2016). The dark side of the moon: meta-analytical impact of recruitment strategies on risk enrichment in the clinical high risk state for psychosis. Schizophrenia Bulletin 42(3), 732-743. DOI: https://doi.org/ 10.1093/schbul/sbv162

Fusar-Poli, P., Sullivan, S. A., Shah, J. L., \& Uhlhaas, P. J. (2019). Improving the Detection of Individuals at Clinical Risk for 
Psychosis in the Community, Primary and Secondary Care: An Integrated Evidence-Based Approach. Frontiers in Psychiatry 10, 774. DOI: https://doi.org/10.3389/fpsyt. 2019.00774

Fusar-Poli, P., Werbeloff, N., Rutigliano, G., Oliver, D., Davies, C., Stahl, D., (...) Osborn, D. (2019). Transdiagnostic Risk Calculator for the Automatic Detection of Individuals at Risk and the Prediction of Psychosis: Second Replication in an Independent National Health Service Trust. Schizophrenia Bulletin 45(3), 562-570. DOI: https://doi.org/10.1093/schbul/ sby070

Ghio, L., Gotelli, S., Marcenaro, M., Amore, M., \& Natta, W. (2014). Duration of untreated illness and outcomes in unipolar depression: a systematic review and meta-analysis. Journal of Affective Disorders, 152-154, 45-51. DOI: https:// doi.org/10.1016/j.jad.2013.10.002

Goldman, H. H., Skodol, A. E., \& Lave, T. R. (1992). Revising axis V for DSM-IV: A review of measures of social functioning. American Journal of Psychiatry 149(9), 1148-1156. DOI: https://doi.org/10.1176/ajp.149.9.1148

Goodwin, R. D., \& Hamilton, S. P. (2002). The early-onset fearful panic attack as a predictor of severe psychopathology. Psychiatry Research 109(1), 71-79. DOI: https://doi.org/ 10.1016/S0165-1781(01)00357-2

Gowers, S. G., Harrington, R. C., Whitton, A., Lelliott, P., Beevor, A., Wing, J., \& Jezzard, R. (1999). Brief scale for measuring the outcomes of emotional and behavioural disorders in children. Health of the Nation Outcome Scales for Children and Adolescents (HoNOSCA). British Journal of Psychiatry 174(MAY), 413-416. DOI: https://doi.org/10.1192/bjp. 174.5.413

Green, A. C., Hunt, C., \& Stain, H. J. (2012). The delay between symptom onset and seeking professional treatment for anxiety and depressive disorders in a rural Australian sample. Social Psychiatry and Psychiatric Epidemiology 47(9), 1475-1487. DOI: https://doi.org/10.1007/s00127-011-0453-x

Hamilton, M. (1959). The assessment of anxiety states by rating. British Journal of Medical Psychology 32(1), 50-55. DOI: https://doi.org/10.1111/j.2044-8341.1959.tb00467.x

Hamilton, M. (1960). A rating scale for depression. Journal of Neurology, Neurosurgery, and Psychiatry 23, 56-62. DOI: https://doi.org/10.1136/jnnp.23.1.56

Hudson, J. I., Hiripi, E., Pope, H. G., \& Kessler, R. C. (2007). The Prevalence and Correlates of Eating Disorders in the National Comorbidity Survey Replication. Biological Psychiatry 61(3), 348-358. DOI: https://doi.org/10.1016/j.biopsych.2006. 03.040

Hung, C. I., Liu, C. Y., \& Yang, C. H. (2017). Untreated duration predicted the severity of depression at the two-year followup point. PLoS ONE 12(9). DOI: https://doi.org/10.1371/journal.pone. 0185119

Hung, C. I., Yu, N. W., Liu, C. Y., Wu, K. Y., \& Yang, C. H. (2015). The impact of the duration of an untreated episode on improvement of depression and somatic symptoms. Neuropsychiatric Disease and Treatment 11, 2245-2252. DOI: https://doi.org/10.2147/NDT.S89498

Kamaradova, D., Latalova, K., Prasko, J., Kubinek, R., Vrbova,
K., Mainerova, B., (...) Tichackova, A. (2016). Connection between self-stigma, adherence to treatment, and discontinuation of medication. Patient Preference and Adherence. DOI: https://doi.org/10.2147/PPA.S99136

Kisely, S., Scott, A., Denney, J., \& Simon, G. (2006). Duration of untreated symptoms in common mental disorders: Association with outcomes. British Journal of Psychiatry 189(JULY), 79-80. DOI: https://doi.org/10.1192/bjp.bp.105.019869

McGorry, P. D., Hartmann, J. A., Spooner, R., \& Nelson, B. (2018). Beyond the \&quot; at risk mental state\&quot; concept: transitioning to transdiagnostic psychiatry. World Psychiatry: Official Journal of the World Psychiatric Association (WPA) 17(2), 133-142. DOI: https://doi.org/10.1002/wps.20514

Medeiros, G. C., Senço, S. B., Lafer, B., \& Almeida, K. M. (2016). Association between duration of untreated bipolar disorder and clinical outcome: Data from a Brazilian sample. Revista Brasileira de Psiquiatria 38(1), 6-10. DOI: https://doi.org/ 10.1590/1516-4446-2015-1680

Parellada, M. (2013). Why psychogeriatrics starts right after adolescence. European Child and Adolescent Psychiatry 22(7), 391-393. DOI: https://doi.org/10.1007/s00787-013-0434-6

Penttilä, M., Jaäskelainen, E., Hirvonen, N., Isohanni, M., \& Miettunen, J. (2014). Duration of untreated psychosis as predictor of long-term outcome in schizophrenia: Systematic review and meta-analysis. British Journal of Psychiatry, Vol. 205, pp. 88-94. DOI: https://doi.org/10.1192/bjp.bp.113.127753

Pirkis, J. E., Burgess, P. M., Kirk, P. K., Dodson, S., Coombs, T. J., \& Williamson, M. K. (2005). A review of the psychometric properties of the Health of the Nation Outcome Scales (HoNOS) family of measures. Health and Quality of Life Outcomes, Vol. 3. DOI: https://doi.org/10.1186/1477-7525-3-76

Thorup, A., Petersen, L., Jeppesen, P., Ohlenschlæger, J., Christensen, T., Krarup, G., (...) Nordentoft, M. (2007). Gender differences in young adults with first-episode schizophrenia spectrum disorders at baseline in the Danish OPUS study. Journal of Nervous and Mental Disease, 195(5), 396-405. DOI: https://doi.org/10.1097/01.nmd.0000253784.59708.dd

van Meter, A. R., Burke, C., Youngstrom, E. A., Faedda, G. L., \& Correll, C. U. (2016). The Bipolar Prodrome: Meta-Analysis of Symptom Prevalence Prior to Initial or Recurrent Mood Episodes. Journal of the American Academy of Child and Adolescent Psychiatry, Vol. 55, pp. 543-555. DOI: https://doi.org/10.1016/j.jaac.2016.04.017

van Os, J., \& Guloksuz, S. (2017). A critique of the 'ultra-high risk' and 'transition' paradigm. World Psychiatry 16(2), 200206. DOI: https://doi.org/10.1002/wps.20423

Wing, J. K., Beevor, A. S., Curtis, R. H., Park, S. B. G., Hadden, S., \& Burns, A. (1998). Health of the nation outcome scales (HoNOS): Research and development. British Journal of Psychiatry Vol. 172, pp. 11-18. DOI: https://doi.org/10.1192/ bjp. 172.1 .11

Yung, A. R., Yuen H. P., Mcgorry, P. D., Phillips, L. J., Kelly, D., (...) Buckby, J. (2005). Mapping the Onset of Psychosis: The Comprehensive Assessment of At-Risk Mental States. Australian \& New Zealand Journal of Psychiatry 39(11-12), 964-971. DOI: https://doi.org/10.1080/j.1440-1614.2005. 01714.x 